\title{
Recorregut de recerca geològica per la comarca de la Segarra: des de Cervera a Sant Pere dels Arquells i Rubinat; i des de les Oluges a Sant Ramon
}

Josep Maria Mata-Perelló

Joaquim Sanz Balagué

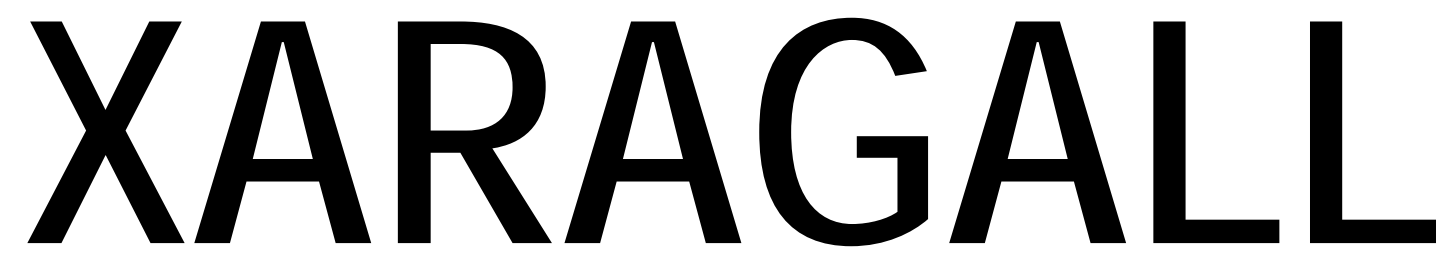

REVISTA DE CIÈNCIES DE LA CATALUNYA CENTRAL

\section{n. 11}

NOVEMBRE 2014 


\section{RECORREGUT DE RECERCA GEOLÒGICA PER LA COMARCA DE LA SEGARRA: DES DE CERVERA A SANT PERE DELS ARQUELLS I RUBINAT; I DES DE LES OLUGES A SANT RAMON}

\section{Josep Maria Mata-Perelló}

Museu de geologia Valentí Masachs, Escola Politècnica Superior d'Enginyeria de Manresa (EPSEM), Universitat Politècnica de Catalunya · BarcelonaTech (UPC), 08272 Manresa, Spain

\section{Joaquim Sanz Balagué}

Departament d'Enginyeria Minera i Recursos Naturals (EMRN), Escola Politècnica Superior d'Enginyeria de Manresa (EPSEM), Universitat Politècnica de Catalunya - BarcelonaTech (UPC), 08272 Manresa, Spain

Paraules clau: Depressió Geològica de l'Ebre, materials terciaris, materials quaternaris, Patrimoni miner

\section{Resum}

Itinerari realitzat el 27 d'octubre de 2013. En aquesta ocasió, es realitzarà un recorregut geològic a través de diferents indrets de la Depressió Geològica de L'Ebre; i més concretament pels sectors corresponents a la seva Depressió Central. Així, tot el recorregut transitarà entre afloraments dels materials terciaris (de l'Eocè i de l'Oligocè) i quaternaris que reblen aquesta depressió.

Així, al llarg de tot el recorregut de l'itinerari es transitarà per la comarca de la Segarra, des del principi fins a la fi. 


\section{Objectius fonamentals}

Els objectius fonamentals que es pretenen aconseguir en aquest itinerari, es poden concretar en els següents aspectes generals:

1. Observació i descripció dels materials terciaris (exclusivament del Paleogen, i més concretament de I'Eocè i de I'Oligocè) de la Depressió Geològica de I'Ebre (i més exactament de la seva Depressió Central). Així, el recorregut de l'itinerari discorrerà entre els afloraments del Complex Lacustre de la Segarra (amb les calcàries de la Panadella, ja de I'Oligocè). Tots aquests terrenys constitueixen el subsòl dels diferents sectors, per entre els quals discorre el present itinerari.

2. Observació de les estructures locals de la Depressió Geològica de l'Ebre, al llarg del recorregut de l'itinerari; tot i això, no cal oblidar que el recorregut transitarà per una de les zones més estables de la depressió, alterada solament per alguns plecs relacionats amb els nivells de guixos.

3. Observació de les explotacions relacionades amb els materials anteriors, com les següents, d'acord amb el sentit de la marxa de l'itinerari:

3A) de les ja esmentades explotacions guixoses de les immediacions de Rubinat, ubicades als Guixos de Talavera.

3B) i de les explotacions de calcolutites grisenques, situades entre els guixos de Talavera (de la Formació Tàrrega), que trobarem a Sant Pere dels Arquells.

3C) de les explotacions dels materials carbonatats de la Panadella-Carbasí, relacionades sobre els nivells de les calcàries de la Panadella de la Formació Tàrrega. Les veurem prop de Sant Ramon.

4. En tots els casos, a les explotacions anteriors, s'observaran les restauracions efectuades en elles.

5. S'observaran, al llarg de tot el recorregut, els diferents elements relacionats amb el Patrimoni Geològic i Miner- 


\section{Antecedents}

Pel que fa al recorregut del present itinerari, existeixen diversos antecedents bibliogràfics. Entre aquests, farem esment de dos treballs nostres, els quals segueixen uns recorreguts bastant semblants i propers al present. Es tracta de: Mata-Perelló (1996a, 1996b, 1996c, 1997, 1999, 2000 i 2001a, 2001b, 2005, 2008 i 2011).

Pel que fa a la descripció de les mineralitzacions, seguirem fent esment d'alguns altres treballs nostres: Mata-Perelló (1990, 1991 i 1995); el primer relatiu a la comarca d'Anoia, el segon al conjunt de les les mineralitzacions catalanes i el tercer a la Segarra. També cal parlar del treball de Colldeforns i Mata-Perelló (1995).

I, finalment, pel que fa a l'estructura geològica de la zona per la qual discorre l'itinerari, farem esment dels treballs de: GUIMERÀ et altri (1982) i de RIBA et altri (1976). També es pot fer esment del treball de Colldeforns - Mata (1987)

Tots aquests treballs referenciats, i d'altres, figuren esmentats per ordre alfabètic a l'apartat dedicat a la BIBLIOGRAFIA.

\section{Recorregut de l'itinerari}

El recorregut de l'itinerari discorrerà íntegrament per la comarca de la Segarra dintre de la Catalunya Central. Així, el recorregut de l'itinerari, s'iniciarà al terme de Cervera, des d'on s'anirà cap a les immediacions de Rubinat. Prop d'aquesta població i la d' Hostalet, es realitzarà la primera aturada.

Després, el recorregut es dirigirà cap a Sant Pere dels Arquells, prop d'on es farà una nova aturada. Després śanirà cap a Vergós i cap a les immediacions de la ciutat segarrenca de Cervera.

Quasi en arribar-hi, es continuarà cap a llevant, anat ara cap a les Oluges i cap a les immediacions de Sant Ramon, per on es farà la darrera aturada del recorregut d'aquest itinerari.

\section{Advertiments previs}

Com en altres recorreguts de RECERCA GEOLÒGICA I MINERALÒGICA... si es disposa del temps suficient, poden efectuar-se passant per totes les parades i filloles. En cas contrari, recomanem prescindir de les anomenades PARADES - CONDICIONALS.

Cal tenir, com sempre, una cura molt especial de respecte a la natura, al llarg de tot el recorregut de l'itinerari, i també fora d'ell. 


\section{Descripció de l'itinerari}

Com de costum, estructurarem el recorregut de I'itinerari en una sèrie de PARADES, que anirem veient. En cadascuna d'aquestes aturades farem un breu comentari (geològic 0 mineralògic, segons s'escaigui). En cada cas indicarem, entre parèntesi, el full topogràfic on es troba l'aturada.

En aquest cas, el recorregut de l'itinerari s'inclourà dintre dels següents fulls, del "Mapa Topográfico Nacional", realitzats a I'escala 1:50.000 per I'I.G.C. de España": 390 (dit de Cervera) i 391 (o d'Igualada).

Així doncs, la relació de les aturades, que composen el recorregut d'aquest itinerari és la següent

\subsection{Parada 1. FORNS DE CALÇ i FORNS DE GUIX DE RUBINAT - L'HOSTALET, (Rubinat i Hostalet, terme municipal de Sant Antolí i Vilanova, comarca de la Segarra). (Full 390).}

El recorregut del present itinerari l'iniciarem a la ciutat de Cervera. A partir d'aquí, ens caldrà agafar la carretera nacional N - II, anant cap a llevant. Així, passarem per les immediacions de Vergós i de Sant Pere dels Arquells. Poc després, arribarem al poble d'Hostalet, des d'on anirem cap a Rubinat, utilitzant la carretera local $L-203$. A uns $2-3 \mathrm{Km}$ d'Hostalet, farem la primera aturada. Així, des de l'inici, haurem recorregut uns $10-11 \mathrm{Km}$. Tot i així, en el trajecte d'Hostalet a Rubinat (d'uns $4 \mathrm{Km}$ ), podem una aturada a qualsevol dels antics Forns de Calç 0 Forns de Guix, que hi a la dreta de la carretera, tot pujant.

En aquest recorregut, hem anat trobant afloraments dels materials cenozoics que formen part del Complex Lacustre de la Segarra. Fonamentalment, haurem trobat trams de calcolutites i de guixos.

En aquest indret (com en altres propers) aquests materials han estat explotats, per a ser emprats com a matèria prima pels Forns de Guix i pels Forns de Calç. A l'indret de la present aturada en trobem alguns d'ells.

Cal considerar que tots ells formen part del nostre Patrimoni Miner, i en especial del Patrimoni Miner de la comarca de la Segarra. 


\subsection{Parada 2. CAMí DE MAS CLARET, (Sant Pere dels Arquells, terme de Sant Antolí, comarca de la Segarra). (Full 390).}

Des de la parada anterior, cal acabar d'arribar a l'Hostalet, per tal de continuar cap a llevant (ara per la carretera N-II, tot descendent per la vall del Riu d'Ondara. Després, en arribar a la cruïlla de Sant Pere dels Arquells, cal agafar el camí que surt per la banda dreta de la carretera (en sentit oposat a la carretera que condueix al poble esmentat). Així cal agafar el camí que en un principi es dirigeix cap a Mas Claret, per tal de fer una fillola. Així, s'hauran recorregut uns $4 \mathrm{Km}$ i escaig.

A molt poca distancia de l'inici del camí (a uns $10 \mathrm{~m}$ ), es troba un trencall per l'esquerra, que condueix a unes antigues explotacions dels guixos de la sots-unitat dels guixos de Talavera, situades molt a prop.

Tanmateix es troben uns antics forns de guix (PARADA 2-BIS). Entre els minerals presents a aquests antics nivells explotats, cal fer esment de la presència d'ANHIDRITA, HEMIHEDRITA i GUIX (el més abundant dels tres),

Malgrat això, el camí principal (el que condueix cap a Mas Claret), ens apropa a uns forns de tostació de materials margosos, on són tractats els extrets d'una propera pedrera, actualment en explotació, que es troba a l'esquerra del camí principal.

En aquesta parada, es pot observar l'explotació de les calcolutites blanquinoses, de la Formació Tàrrega, i alhora es poden observar les instal-lacions dels forns. Tot i així, per a l'observació dels esmentats forns de tostació, i de la pedrera en explotació, es necessari gaudir de la corresponent autorització de l'empresa minera concessionària de l'esmentada explotació. (fotografies 1 i 2 ).

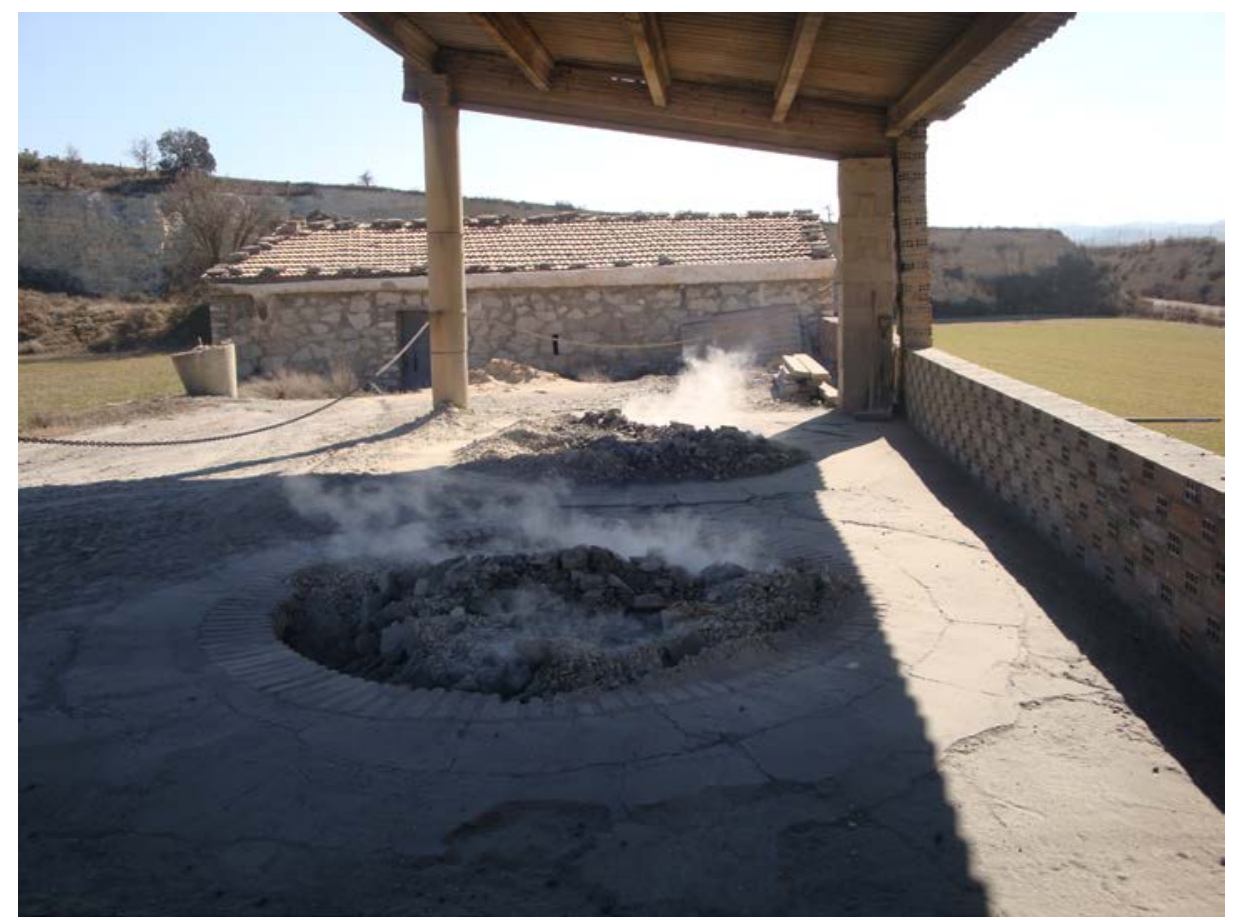

Fotografia 1. Un aspecte de la part superior del Forn de Calç de sant Pere dels Arquells 


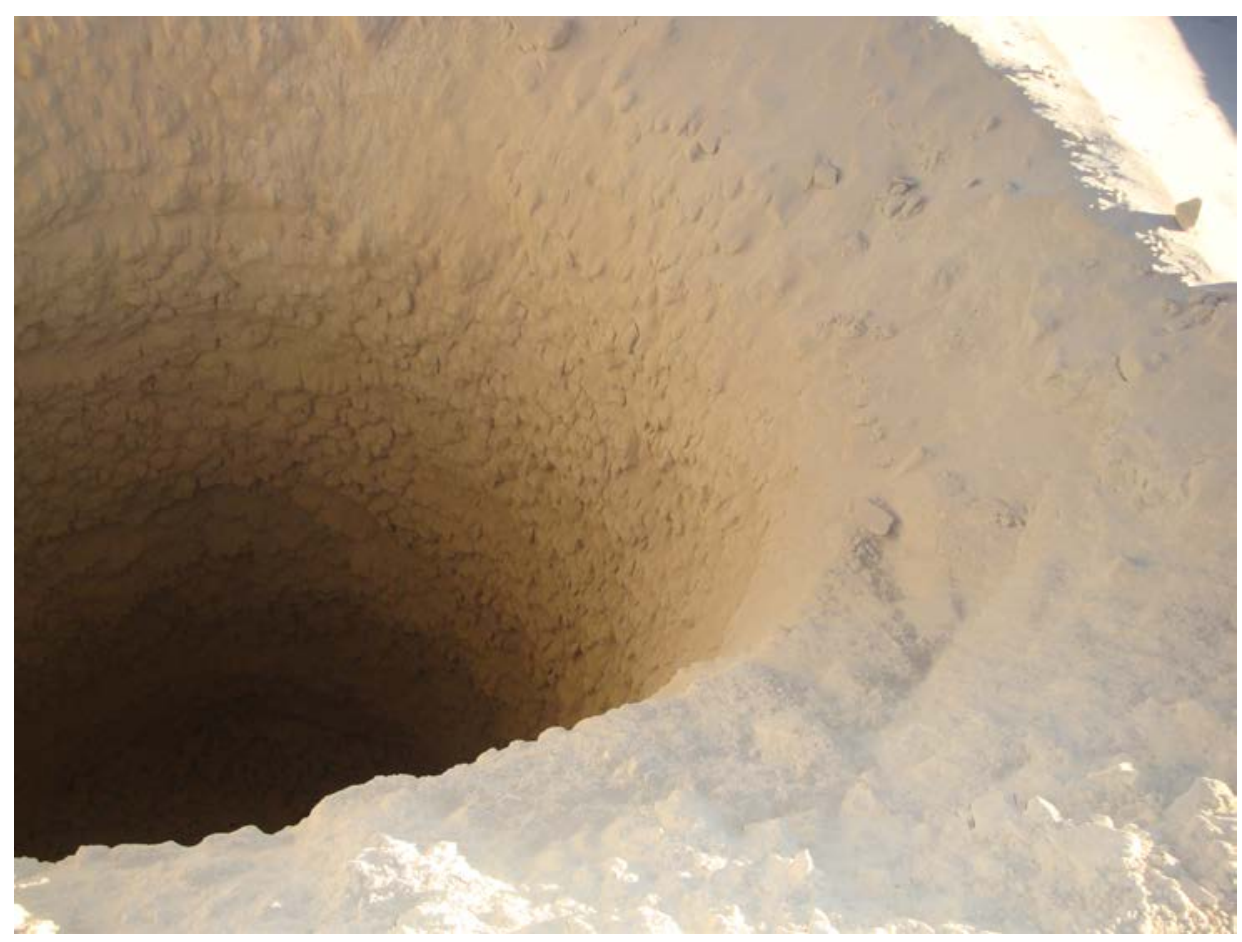

Fotografia 2. Un aspecte de la boca superior del Forn de Calç de sant Pere dels Arquells

\subsection{Parada 3. TÚNEL DE CERVERA, (terme municipal de Cervera, comarca de la Segarra). (Full 390)}

Després de fer l'aturada anterior, cal retornar a l'antiga carretera N-II, per tal de continuar el recorregut cap a la població de Vergós i tot seguit cap a la de Cervera. En arribar a les immediacions del Túnel es farà aquesta darrera aturada, a uns $6 \mathrm{Km}$ de l'anterior.

En aquest recorregut, primer haurem anat trobant els nivells anteriorment esmentats dels guixos de Talavera (precisament, en passar per les immediacions de Vergós haurem vist uns interessants plecs, dibuixats per aquests materials, a la vora de la carretera).

Després, en arribar a les immediacions de Cervera, en pujar la cuesta, haurem trobat els nivells de les calcàries de Cervera. Aquests són els materials que apareixen a l'indret de l'aturada. Com els anteriors, formen part de la Formació Tàrrega. 


\subsection{Parada 4. PEDRERA DE CALCÀRIES DE SANT RAMON, (terme municipal de Sant Ramon, comarca de la Segarra). (Full 390)}

Després de fer l'aturada anterior, cal sortir des de Cervera cap a llevant. Així, ens caldrà agafar la carretera autonòmica $\mathrm{C}-25$. Per aquesta anirem cap a les Oluges i posteriorment cap a Sant Ramon (anant ara per I'antiga carretera nacional N - 141). Abans d'arribar a aquest darrer poble, trobarem una antiga pedrera situada a l'esquerra de la carretera. En aquest indret farem una nova aturada, a uns $11 \mathrm{Km}$ de la parada anterior, aproximadament.

En aquest recorregut, hem anat trobant els materials esmentats a les aturades anteriors, fonamentalment els nivells de calcolutites del Complex Al/luvial de la Segarra. Tot i així, en aquest indret hi ha una antiga explotació minera, on s'aprofitaven els nivells de les calcàries del Paleogen.

En aquest indret finalitza el recorregut de l'itinerari.

\section{Bibliografia}

COLLDEFORNS, B. I MATA-PERELLÓ, J.M. (1987).- Inventari mineralògic de la comarca de la Segarra, Xaragall, $\mathrm{n}^{\circ}$ 18, 32 pag. Manresa.

GUIMERÀ, J. et altri (1992).- Geologia (II), Història Natural dels Països Catalans, Vol.2, 547 pag. Enciclopèdia Catalana, S.A. Barcelona.

MATA-PERELLÓ, J.M. (1991).- Els Minerals de Catalunya. Arxius de la Secció de Ciències, t. XCIII, 442 pag. Institut d'Estudis Catalans. Barcelona.

MATA-PERELLÓ, J.M. (1996a).- Recerca geològica i mineralògica per les comarques d'Anoia, Segarra, Conca de Barberà, Urgell i Noguera: des de la Panadella a Preixens. Inèdit, 18 pàgines. Manresa.

MATA-PERELLÓ, J.M. (1996b).- Selecció d'Itineraris Geològics i Mineralògics per les terres de Lleida, Pub. EUPM-Museu de Geologia, 65 pàgines. Manresa.

MATA-PERELLÓ, J.M. (1996c).- Recerca geològica i mineralògica per les comarques d'Anoia, Segarra, Conca de Barberà, Segarra i Urgell: des de Jorba a Preixens. Inèdit, 19 pàgines, Manresa.

MATA-PERELLÓ, J. M. (2001a).- Recerca geològica i geoambiental per les comarques d'Anoia i de la Segarra: des d'Òdena i l'Espelt cap a Sant Genís i Jorba, i des de Montmaneu a Sant Pere dels Arquells. Inèdit, 8 pàgines. Manresa.

MATA-PERELLÓ, J. M. (2001b).- Recorregut de recerca de geologia ambiental per les comarques de la Segarra, de l'Urgell i de les Garrigues: des la Panadella i Santa Coloma de Queralt cap a Guimerà i cap a Belianes. Inèdit, 10 pag. Manresa.

MATA-PERELLÓ, J. M. (2011).- Recorregut de recerca geològica i geoambiental per les comarques d'Anoía i de la Segarra: des d'Òdena i Castellolí cap a Jorba, Carbasí, Rubinat i Cervera. Algeps ñ 311.12 pàgines. Manresa. 
MATA-PERELLÓ, J.M. i COLLDEFORNS, B. (1995).- Introducció al coneixement geològic de la Segarra. Coneix. de l'entorn natural de la Segarra, $n^{0} 7,29 p a g$. Cervera.

RIBA, O. et altri (1976).- Geografia Física dels Països Catalans, Edit. Ketres, 254 pàgines. Barcelona. 